\title{
Cervical disc arthroplasty with PRESTIGE LP disc versus anterior cervical discectomy and fusion: a prospective, multicenter investigational device exemption study
}

\author{
Matthew F. Gornet, MD, ${ }^{1}$ J. Kenneth Burkus, MD, ${ }^{2}$ Mark E. Shaffrey, MD, ${ }^{3}$ Perry J. Argires, MD, ${ }^{4}$ \\ Hui Nian, PhD, ${ }^{5}$ and Frank E. Harrell Jr., $\mathrm{PhD}^{5}$
}

${ }^{1}$ The Orthopedic Center of St. Louis, Missouri; ${ }^{2}$ Wilderness Spine Services, The Hughston Clinic, Columbus, Georgia; ${ }^{3}$ Department of Neurosurgery, University of Virginia Health System, Charlottesville, Virginia; ${ }^{4}$ Brain Orthopedic Spine Specialists, Lancaster, Pennsylvania; and ${ }^{5}$ Department of Biostatistics, Vanderbilt University School of Medicine, Nashville, Tennessee

\begin{abstract}
OBJECT This study compared the safety and efficacy of treatment with the PRESTIGE LP cervical disc versus a historical control anterior cervical discectomy and fusion (ACDF).

METHODS Prospectively collected PRESTIGE LP data from 20 investigational sites were compared with data from 265 historical control ACDF patients in the initial PRESTIGE Cervical Disc IDE study. The 280 investigational patients with single-level cervical disc disease with radiculopathy and/or myelopathy underwent arthroplasty with a low-profile artificial disc. Key safety/efficacy outcomes included Neck Disability Index (NDI), Neck and Arm Pain Numerical Rating Scale scores, 36-Item Short Form Health Survey (SF-36) score, work status, disc height, range of motion, adverse events (AEs), additional surgeries, and neurological status. Clinical and radiographic evaluations were completed preoperatively, intraoperatively, and at 1.5, 3, 6, 12, and 24 months postoperatively. Predefined Bayesian statistical methods with noninformative priors were used, along with the propensity score technique for controlling confounding factors. Analysis by independent statisticians confirmed initial statistical findings.
\end{abstract}

RESULTS The investigational and control groups were mostly similar demographically. There was no significant difference in blood loss ( $51.0 \mathrm{ml}$ [investigational] vs $57.1 \mathrm{ml}$ [control]) or hospital stay ( 0.98 days [investigational] vs 0.95 days [control]). The investigational group had a significantly longer operative time (1.49 hours vs 1.38 hours); $95 \%$ Bayesian credible interval of the difference was $0.01-0.21$ hours. Significant improvements versus preoperative in NDI, neck/arm pain, SF-36, and neurological status were achieved by 1.5 months in both groups and were sustained at 24 months. Patient follow-up at 24 months was $97.1 \%$ for the investigational group and $84.0 \%$ for the control group. The mean NDI score improvements versus preoperative exceeded 30 points in both groups at 12 and 24 months. SF-36 Mental Component Summary superiority was established (Bayesian probability 0.993 ). The mean SF-36 PCS scores improved by 14.3 points in the investigational group and by 11.9 points in the control group from baseline to 24 months postoperatively. Neurological success at 24 months was $93.5 \%$ in the investigational group and $83.5 \%$ in the control group (probability of superiority 1.00). At 24 months, $12.1 \%$ of investigational and $15.5 \%$ of control patients had an AE classified as device or device/surgical procedure related; $14(5.0 \%)$ investigational and $21(7.9 \%)$ control patients had a second surgery at the index level. The median return-to-work time for the investigational group was 40 days compared with 60 days for the control group $p=0.020$ after adjusting for preoperative work status and propensity score). Following implantation of the PRESTIGE LP device, the mean angular motion was maintained at 12 months $\left(7.9^{\circ}\right)$ and 24 months $\left(7.5^{\circ}\right)$. At 24 months, $90.0 \%$ of investigational and $87.7 \%$ of control patients were satisfied with the results of surgery. PRESTIGE LP superiority on overall success (without disc height success), a composite safety/efficacy end point, was strongly supported with 0.994 Bayesian probability.

\footnotetext{
ABBREVIATIONS ACDF = anterior cervical discectomy and fusion; $A E=$ adverse event; $A S D=$ adjacent-segment disease; $C D A=$ cervical disc arthroplasty; $D D D=$ degenerative disc disease; $\mathrm{FSU}$ = functional spinal unit; $\mathrm{HPD}$ = highest posterior density; IDE = investigational device exemption; $\mathrm{MCS}$ = Mental Component Summary; NDI = Neck Disability Index; PCS = Physical Component Summary; SF-36 = 36-Item Short Form Health Survey.

SUBMITTED June 19, 2014. ACCEPTED January 27, 2015.

INCLUDE WHEN CITING Published online July 31, 2015; DOI: 10.3171/2015.1.SPINE14589.

DISCLOSURE This investigational device exemption study was sponsored by Medtronic (Memphis, TN). The authors report the following potential or perceived conflicts: Dr. Gornet owns shares (Bonovo, Nocimed, OuroBoros, Paradigm Spine, K2M, International Spine, and Orthopedic Institute) and receives royalties for design of an unrelated product (Medtronic and Pioneer). Dr. Burkus is a consultant (Zimmer/Biomet and Medtronic), patent holder (Zimmer/Biomet and Medtronic), receives royalties (Zimmer/ Biomet and Medtronic), and receives research support (Medtronic). Dr. Nian reports a financial relationship for statistical analysis for the study/writing or editorial assistance on the manuscript (Medtronic).
} 
CONCLUSIONS This device maintains mean postoperative segmental motion while providing the potential for biomechanical stability. Investigational patients reported significantly improved clinical outcomes compared with baseline, at least noninferior to ACDF, up to 24 months after surgery.

Clinical trial registration no.: NCT00667459 (clinicaltrials.gov)

http://thejns.org/doi/abs/10.3171/2015.1.SPINE14589

KEY WORDS cervical disc arthroplasty; anterior cervical discectomy and fusion; artificial cervical disc; cervical radiculopathy; cervical myelopathy; adjacent level disease

$\mathrm{P}$ ATIENTS with intractable neck pain or increasing neurological deficit due to cervical spondylosis or disc herniation with radiculopathy and/or myelopathy, in whom nonoperative treatment modalities and therapy have failed, are appropriate candidates for surgical decompressive surgery. Anterior cervical discectomy and fusion $(\mathrm{ACDF})$ has been the standard of care for more than 50 years, ,2,40,27 providing effective relief of patient symptoms by decompressing the neural elements and permanently stabilizing the functional spinal unit (FSU). In recent years, anterior cervical decompression and fusion with allograft bone and anterior plate fixation has contributed to better outcomes due to improved lordosis and reduced pseudoarthrosis..$^{4,6,10,14,32}$ However, complications including adjacent-segment degeneration (ASD), screw loosening, and plate-related complications have been widely reported. $1,13,15,32$

In response to these concerns and a nascent body of evidence in support of lumbar total disc replacement, ${ }^{11,33}$ cervical disc arthroplasty (CDA) devices were developed and implanted beginning in the 1990s. ${ }^{7}$ In the United States, clinical trials of these cervical disc prostheses were initiated beginning in $2002,{ }^{3}$ offering the potential to restore and/or maintain anatomical disc space height, normal lordosis, and physiological motion in the cervical spine with the theoretical benefit of decreased ASD and other fusion morbidities. The first of several large, randomized controlled trials comparing CDA with ACDF began in 2002. As of this writing, a total of 7 CDA devices have been approved by the FDA after demonstrating outcomes at least comparable to ACDF for treatment of symptomatic cervical degenerative disc disease (DDD). ${ }^{5,8,21-23,26,30}$

This study reports 2-year results of the FDA-approved investigational device exemption (IDE) study for the PRESTIGE LP Cervical Disc (Medtronic). The device is an unconstrained ball-in-trough, metal-on-metal articulation manufactured from a titanium ceramic composite.

\section{Methods \\ Study Design}

The study was approved by the Hughston Sports Medicine Center Institutional Review Board on January 7, 2005. From January to November 2005, 280 nonrandomized patients at 20 investigational sites in this FDA IDE trial (clinicaltrials.gov: NCT00667459) received treat- ment by 50 investigators and coinvestigators for singlelevel cervical degenerative disc disease using a low-profile CDA device. The safety and efficacy outcomes for these patients were compared with data from the 265 historical control patients from a previous FDA-approved IDE study (clinicaltrials.gov: NCT00642876) with identical inclusion and exclusion criteria ${ }^{21}$ who underwent ACDF with allograft bone and an anterior plate, utilizing a similar surgical approach. Patients were evaluated preoperatively, intraoperatively, and at routine postoperative intervals of $1.5,3,6,12$, and 24 months.

\section{Independent Data Review}

Consistent with an emerging trend ${ }^{9,16}$ but still rare for an FDA IDE study of a spinal implant device, the study sponsor delivered the entire raw data set to a team of independent statisticians at Vanderbilt University for analysis. Using the identical methods from the original FDA-approved statistical analysis plan in the study protocol, the independent analysis reached the same statistical conclusions as the study sponsor for all proposed comparisons. Whereas the sponsor statisticians used the statistical software SAS (SAS Institute) to generate the summary tables and WinBUGS to conduct the Bayesian analysis, the independent statisticians used $\mathrm{R}$ software to generate the summary tables and JAGS to conduct the Bayesian analysis.

\section{Statistical Analysis}

The results of FDA IDE studies for spinal devices have been almost exclusively reported using the Frequentist approach in the peer-reviewed literature. In the Frequentist approach, evidence for efficacy is generally thought to be provided by $\mathrm{p} \leq 0.05$. This is the probability of observing, over repetitions of the same experiment, a test statistic as impressive as or more impressive than the observed statistic for comparing 2 groups if the null hypothesis is true. Bayesian results are "positive," by comparison, when, for example, the posterior probability of efficacy is $\geq 0.95$. For assessing evidence, the Bayesian posterior probability of a statement such as "Treatment 1 tends to be better than Treatment 2 " is the probability that the statement is true. In addition, the $95 \%$ Bayesian credible intervals are provided for parameters of interest. The primary objective in this study was to show that the overall success rate in the investigational group was statistically noninferior to 
the rate in the historical control group. For deriving the overall success variable-the primary clinical trial end point-and for the purpose of statistical comparisons of secondary end points, the relevant variables were dichotomized as binary, that is, success or failure, using criteria described in the protocol for each specific endpoint. Generally, success was defined as maintenance or improvement compared with the preoperative measure, except for Neck Disability Index (NDI) success, which was defined as at least a 15-point improvement versus baseline.

The primary analysis data set consisted of all patients who received one of the study devices and completed surgical procedures. The outcomes of patients requiring an additional surgical procedure (removal, revision, or supplemental fixation) were recorded as a treatment failure for overall success, the primary study end point, and the last observations taken immediately before the additional surgical procedures/interventions were carried forward for all future evaluation periods. Descriptive statistics were provided for patient demographics, preoperative measures, and outcome measures using median, interquartile, mean, and standard deviation for continuous variables and frequencies for categorical variables. A 2-sample ttest or chi-square test was used to compare demographics and preoperative variables between the investigational and control groups. A paired t-test was used to compare pre- and postoperative changes in the outcomes within each group. Return to work was compared between the 2 groups using a log-rank test.

To adjust for any possible effects of demographic characteristics or preoperative measures on clinical outcomes, the propensity score technique was used. The propensity score was calculated based on a logistic regression model with the following covariates: age, height, weight, sex, race, marital status, education level, work status, workers' compensation, spinal litigation, tobacco use, alcohol use, nonnarcotic pain medication use, weak narcotic pain medication use, strong narcotic pain medication use, muscle relaxant medication use, time to onset of symptoms, and previous neck surgery, as well as treatment level and preoperative scores for NDI, 36-Item Short Form Health Survey (SF-36) Physical Component Summary (PCS), SF36 Mental Component Summary (MCS), neck pain, arm pain, gait, foraminal compression test reaction, and neurological status (motor function, sensory, and reflex). Where an observation was missing for a given demographic/preoperative variable in a particular patient, the mean value of the corresponding treatment group was imputed for the missing data point. Covariate balance after propensity score adjustment was examined using ANCOVA or logistic regression.

Bayesian logistic regression models were fitted for primary outcomes (overall success, individual efficacy, and neurological status success at 24 months) with propensity score used as a covariate. Independent, "noninformative" priors were used for the parameters in the model. Markov chain Monte Carlo simulations were performed to obtain the posterior distributions of the control group success rate and the investigational group success rate, as well as the success rate difference between the treatment groups for an average patient with a propensity score set to be the mean of all patients. The mean of the posterior distributions and 95\% highest posterior density (HPD) were reported. The noninferiority of the investigational treatment to the control treatment was established by demonstrating at least a 0.95 posterior probability that the control success rate was no more than $10 \%$ greater than the investigational success rate. Once noninferiority was demonstrated, superiority was established if the posterior probability of the investigational success rate being greater than the control success rate was at least 0.95 .

Similar models were used to assess adverse events (AEs) and additional surgical procedures or interventions. Bayesian normal linear regression models were fitted for surgery length, blood loss, and hospital stay, and the propensity score was included as a covariate. Independent, "noninformative" priors were used for the parameters in the models, and posterior distributions were calculated for the mean outcome of the control group and the investigational group, as well as the difference between the 2 groups. For these outcomes, superiority of the investigational treatment to the control treatment was established if the posterior probability that the investigational group outcome was better than the control group outcome was at least 0.975 .

Sensitivity analyses were performed for primary outcomes by using "per protocol" and "per protocol, in window" data sets. In the "per protocol" data set, patients who had major protocol deviations were excluded. The "per protocol, in window" data set further excluded any "out of window" visits. We also fitted a Cox proportional hazards model to investigate the time to return to work between the 2 arms; propensity score and preoperative work status were included as covariates. All analyses by the independent statisticians were performed using the software R 3.0.2 (www.R-project.org) and the software JAGS 3.4.0 (Plummer, Martyn: JAGS: A Program for Analysis of Bayesian Graphical Models Using Gibbs Sampling, in Proceedings of the 3rd International Workshop on Distributed Statistical Computing [DSC 2003, Vienna, Austria, 2003]).

\section{Inclusion and Exclusion Criteria}

Study sites with institutional review board approvals consented and enrolled eligible patients (Table 1) with symptomatic cervical DDD requiring surgery at a single level from C-3 to C-7. All had intractable radiculopathy and/or myelopathy recalcitrant to nonoperative treatment modalities, such as reduction of painful activities and an integrated therapy program that may have included neck stabilization exercises, antiinflammatory medications, and other modalities such as traction, massage, and/or moist heat. All patients were considered candidates for a singlelevel standalone ACDF.

\section{Device Design}

The PRESTIGE LP Cervical Disc is a dynamic device made of a titanium ceramic composite that is inserted into the intervertebral disc space of the cervical spine. The device comprises 2 low-profile plates that interface through a ball-in-trough mechanism (Fig. 1), permitting segmental 
TABLE 1. Inclusion and exclusion criteria

\begin{tabular}{|c|c|}
\hline iteria & era \\
\hline $\begin{array}{l}\text { al degenerative disc disease } \\
\text { as: intractable radiculopathy } \\
\text { yelopathy w/ } \geq 1 \text { of the following } \\
\text { roducing symptomatic nerve } \\
\text { or spinal cord compression that } \\
\text { Imented by patient history (e.g., } \\
\text { unctional deficit, \&/or neurologi- } \\
\text { icit radiological studies [e.g., } \\
\text { Rl, x-ray, etc.]): } \\
\text { lerniated disc } \\
\text { steophyte formation } \\
\text { vel requiring surgical treatment } \\
\text { disc to C6-7 disc level of } \\
\text { ment } \\
\text { onsive to nonoperative treat- } \\
\text { or approximately } 6 \text { wks or } \\
\text { ce of progressive symptoms } \\
\text { s of nerve root/spinal cord } \\
\text { ession in the face of continued } \\
\text { the pative management } \\
\text { vious surgical intervention at } \\
\text { olved level or any subsequent, } \\
\text { d/staged surgical procedure at } \\
\text { olved or adjacent level(s) } \\
\text { yrs, inclusive, at the time of } \\
\text { yale of child-bearing potential, } \\
\text { is notive NDI score } \geq 30 \\
\text { oreoperative neck pain score } \\
\text { ised on the Preoperative Neck } \\
\text { y }\end{array}$ & 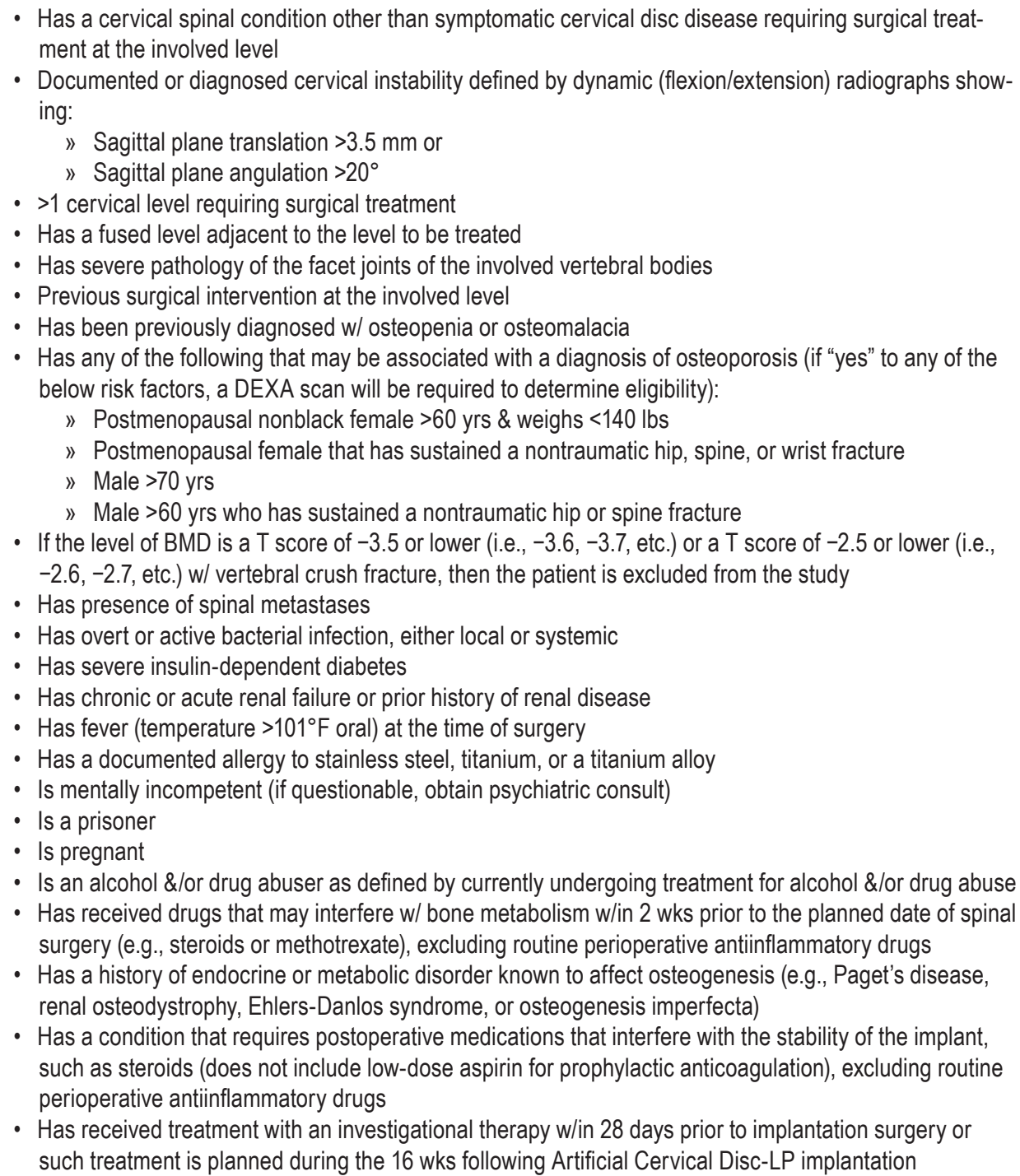 \\
\hline
\end{tabular}

$\mathrm{BMD}=$ bone mineral density; $\mathrm{DEXA}=$ dual-energy $\mathrm{x}$-ray absorptiometry.

spinal motion. The device may also serve to maintain disc space height. Dual serrated keels on each endplate are attached to the vertebral bodies through impaction to stabilize the implant. A titanium plasma spray coating on the osseointegrating surfaces is intended to promote bony ingrowth. The device is available in various combinations of depth and height to accommodate the intervertebral disc space and to engage the adjacent vertebral bodies.

\section{Surgical Procedure and Postoperative Care}

Both the investigational and historical control groups underwent surgery using a similar standard anterior approach to the cervical spine. The level of the disc space was confirmed radiographically, and dissection was not carried out past the midportion of the vertebral bodies adjacent to the operative disc space. The anterior annulus, disc, and cartilaginous endplates were removed. Gentle distraction was carried out, reestablishing the anatomical disc space height using either intradiscal distraction or Caspar vertebral body distraction pins.

The lateral margins of the disc space were exposed, extending superiorly off of the lateral margins of the inferior vertebral body. Hypertrophic uncovertebral joint spurs could be thinned with a high-speed bur; the neuroforamina could be enlarged with a fine curette or thin-footed Kerrison rongeur. The posterior annulus and posterior longitudinal ligament were partially or totally removed based on pathology and the central spinal canal was exposed and decompressed. The depth of the vertebral was precisely measured with a caliper.

In the investigational group, the endplates were preserved. The PRESTIGE LP implant that approximated the depth and height of the interspace was selected. Care was taken not to overdistract the interspace. The adjacent end- 

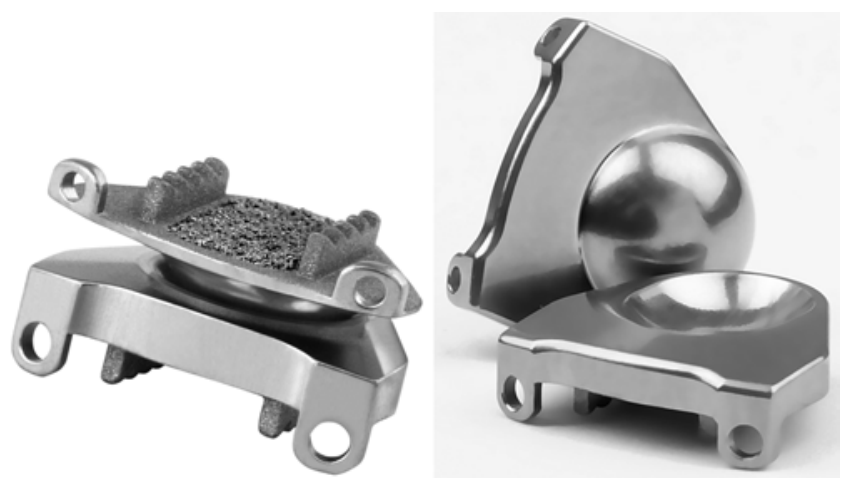

FIG. 1. The PRESTIGE LP device.

plates were prepared utilizing a dual keel-cutting device. The implant was then impacted into the disc space.

In the control fusion group, the vertebral endplates were decorticated. An anterior plate was placed over the allograft (cortical ring) and secured to the adjacent vertebral bodies.

Patients were encouraged to ambulate immediately after surgery, and physical activities were advanced at the discretion of the attending surgeon. Smokers were encouraged to stop smoking. Use of nonsteroidal antiinflammatory drugs was recommended for the first 2 weeks postoperatively, with avoidance thereafter. An external soft-sided orthosis was used at the preference of the attending surgeon.

\section{Clinical Outcome Measurements}

Clinical outcomes were measured by validated instruments: the NDI and the SF-36. ${ }^{19}$ Neck pain and arm pain numeric rating scales (adapted in part from McDowell and $\mathrm{Newell}^{18}$ ), neurological status, patient satisfaction, and work status were also assessed. Patients were examined preoperatively and immediately following surgery and completed self-reported outcomes questionnaires before surgery and at 1.5, 3, 6, 12, and 24 months after surgery.

The primary IDE clinical study end point, as required by FDA and defined in the protocol, was overall success at 24 months (Table 2), which required all of the following: NDI success, neurological success, disc height (FSU height) success, no serious AE classified as implant or implant/surgical procedure associated, and no secondary surgical procedure classified as a "failure."

\section{Radiographic Assessment}

The objective of the radiographic analysis was to characterize the radiographic measurements of the investigational device, in particular disc space height and maintenance of motion. Two independent reviewers from the core laboratory performed radiographic assessment measurements utilizing an orthopedic reading system and digitized images of plain radiographs obtained at scheduled intervals to assess the patients' progress. A third independent reviewer adjudicated conflicting findings.

Using FSU height (Fig. 2) was a surrogate for evaluating the maintenance of disc height or directly determining whether the implant had subsided. Using vertebral endplate distances in the conventional measurement of disc
TABLE 2. Overall success criteria

\begin{tabular}{|c|c|}
\hline Condition* & Definition/Explanation \\
\hline NDI success & $\begin{array}{l}\text { At least } 15 \text {-point improvement postop- } \\
\text { eratively compared to preoperative } \\
\text { score }\end{array}$ \\
\hline $\begin{array}{l}\text { Neurological status suc- } \\
\text { cess }\end{array}$ & $\begin{array}{l}\text { Maintenance or improvement in post- } \\
\text { operative neurological status (motor } \\
\text { function, sensory function, and } \\
\text { reflexes) compared w/ preoperative } \\
\text { condition }\end{array}$ \\
\hline Disc height success & $\begin{array}{l}\text { Functional spinal unit anterior or pos- } \\
\text { terior measurement height declined } \\
\text { by no more than } 2 \mathrm{~mm} \text { compared } \mathrm{w} / \\
\text { the } 6 \text {-wk postoperative assessment }\end{array}$ \\
\hline $\begin{array}{l}\text { No serious adverse event } \\
\text { classified as implant or } \\
\text { implant/surgical proce- } \\
\text { dure associated }\end{array}$ & $\begin{array}{l}\text { Serious adverse event = Grade } 3 \text { or } \\
\text { Grade } 4 \text { per WHO criteria (typically, } \\
\text { resulting in ER visit or hospitaliza- } \\
\text { tion) }\end{array}$ \\
\hline $\begin{array}{l}\text { No secondary surgical } \\
\text { procedure classified as } \\
\text { a "failure" }\end{array}$ & $\begin{array}{l}\text { Supplemental fixation, removal, or revi- } \\
\text { sion = treatment failure; Reopera- } \\
\text { tion or other surgical procedure } \neq \\
\text { treatment failure }\end{array}$ \\
\hline
\end{tabular}

ER = emergency room.

* A patient will be considered an overall success if all conditions are met.

height was thought to be problematic due to visualization challenges created by the investigational implant, despite its low profile. Likewise, formation of a solid fusion mass can potentially obscure 1 or more measurement landmarks in fusion patients. The determination of FSU height success was based on whether either the anterior or posterior measurement had declined by no more than $2 \mathrm{~mm}$

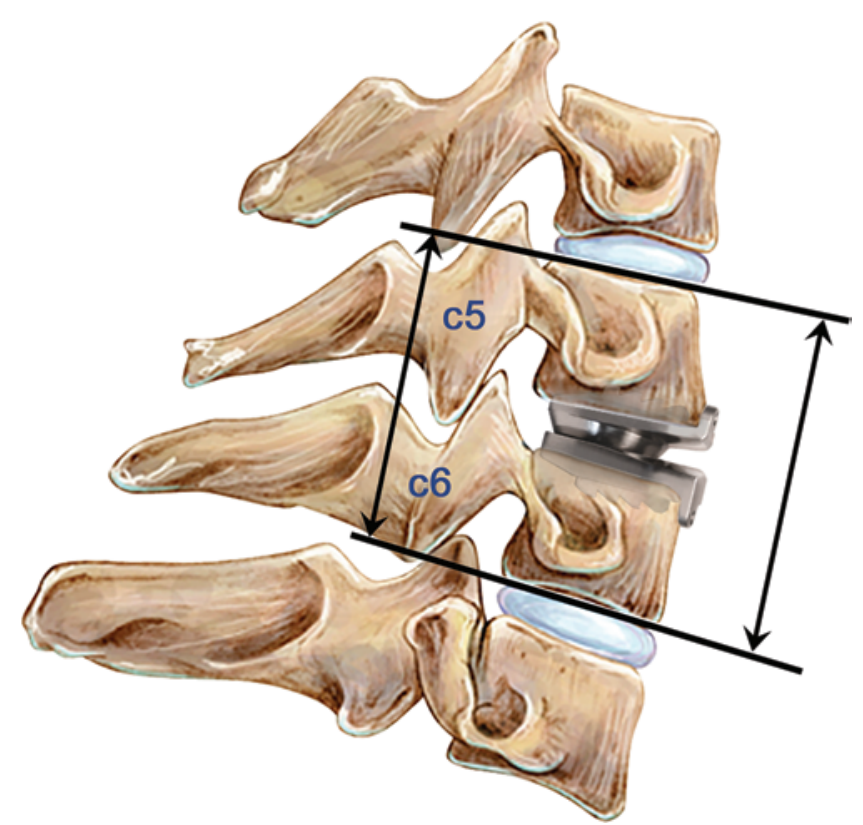

FIG. 2. FSU height was measured anteriorly and posteriorly beginning 6 weeks after surgery. Any decline of more than $2 \mathrm{~mm}$ compared with the 6 -week measurement indicated failure to maintain disc height. Copyright Matthew F. Gornet. Published with permission. 
compared with the 6-week postoperative assessment. FSU height success, although potentially indicative of neither safety nor efficacy, was an FDA-required component of the overall success measurement. Results are given both with and without FSU height success in this report.

\section{Device Safety Evaluation}

The neurological status of the patients was evaluated preoperatively and postoperatively. Overall neurological status success was based on demonstrating maintenance or improvement in each test-motor function, sensory function, and reflexes-compared with the preoperative status.

In addition to neurological success, the safety of the patient's treatment with the investigational device was also evaluated based on the nature and frequency of AEs compared with those occurring in the control group. The primary AE summaries and statistical comparisons are based on a hybrid term/category mapping scheme proposed by the FDA, which draws on the study sponsor's internal process and the MeDRA (Medical Dictionary for Regulatory Activities) coding system to place each of 20 classifications of AEs under a broad body system (for example, neurological, cardiac disorders), incident (for example, trauma, infection), or other (associated conditions/systems with small numerical incidence). Adverse events were characterized by their nature into categories and graded according to WHO criteria as "non-serious" (Grade 1 or 2) or "serious" (Grade 3 or 4) events. ${ }^{31}$

These events were likewise classified according to their potential relation to the implant and/or surgical procedure. The AE relationship and severity determination were performed by an independent, external adjudication committee of 3 physicians, generating data for this publication and the sponsor's premarket application. An AE that resulted in a second surgical procedure would be classified as a "failure" if it required a supplemental fixation, implant removal, or a revision.

\section{Results}

\section{Patient Accountability}

Of the 280 investigational patients enrolled and treated with the PRESTIGE LP device in the study, information was received on 272 patients or $97.1 \%$ at 24 months compared with $84.0 \%$ of the 265 patients for whom any information was received in the control group. On the more conservative basis of counting only patients who had overall success outcomes (without FSU height) at 24 months, similar follow-up rates were achieved $(96.8 \%$ and $83.0 \%$, respectively). For overall success as defined by the FDA in the protocol (including FSU height), $80.7 \%$ of the investigational and $64.5 \%$ of the control patients had outcomes reported at 24 months.

\section{Patient Demographics}

As expected in light of the matching inclusion/exclusion criteria, the investigational and control groups were similar demographically, except for race and tobacco use. The historical control group had a higher percentage of patients using tobacco before their operation; however, fusion rates in the group were greater than $96 \%$, indicating that smoking did not have a significant impact on fusion in that study.

There were no statistically significant differences in terms of preoperative medical history, medical condition, or medication usage. Likewise, there were no statistically significant differences in preoperative status of key efficacy end points (NDI, SF-36, neck and arm pain) between the 2 treatment groups. With respect to neurological status, we found that there was no significant difference in normal reflexes between the groups and that the rates of normal motor function and sensory function were significantly higher in the investigational group. However, all were statistically well balanced after adjusting for propensity score, as indicated in the last 2 columns of Table 3 . In summary, the investigational and historical control groups were comparable prior to surgery. Furthermore, potential confounding effects were statistically adjusted for by using the patient's propensity score as the covariate. This would support that conclusions drawn about safety and efficacy of the investigational device were based on treatment effect rather than confounding factors.

\section{Surgical Data}

All patients were treated using a standard extrapharyngeal anterolateral approach, and more than $90 \%$ of patients in each group were treated at the C5-6 or C6-7 level. Patients were classified as "inpatient" (hospitalization) in $66.4 \%$ of PRESTIGE LP and $69.1 \%$ of ACDF cases. Mean operative time was 1.49 hours in the investigational group and 1.38 hours in the control group, a difference of approximately 6.5 minutes, which was statistically significant (95\% credible interval 0.01-0.21). Blood loss and hospital stay were similar between the groups (Table 4).

\section{Safety Measurements}

The safety of the investigational device was evaluated based on the nature and frequency of AEs compared with those occurring in the control group. Table 5 provides a time course summary of operative and postoperative AEs for both treatment groups. The total number of events per category and the number of patients involved are also reported. Statistical comparisons of the AE occurrence rates were made using predefined Bayesian methods (Table 6). Compared with the ACDF group, the investigational group had a higher rate of AEs categorized as anatomical difficulty, heterotopic ossification, implant event, neurological $\mathrm{AE}$, spinal event, trauma, urogenital AE, vascular AE, and wound (noninfectious). As expected, the rate of nonunion events was significantly higher in the control group.

Adverse events that required a second surgery at the index level were classified as revisions, removals, supplemental fixations, or reoperations. A revision was defined as a procedure that adjusted or in any way modified the original implant configuration. A removal was defined as a procedure that removed 1 or more components of the original implant configuration without replacement with the same type of device. Supplemental fixation was defined as a procedure in which additional spinal devices not approved as part of the protocol were placed, including supplemental treatments such as bone growth stimulators. A reoperation was defined as any surgical procedure at the treated spinal 
TABLE 3. Patient demographic and preoperative characteristics

\begin{tabular}{|c|c|c|c|c|c|}
\hline \multirow[b]{2}{*}{ Variable } & \multirow[b]{2}{*}{$\begin{array}{l}\text { Investigational } \\
\qquad(n=280)^{*}\end{array}$} & \multirow[b]{2}{*}{$\begin{array}{c}\text { Control } \\
(n=265)^{*}\end{array}$} & \multirow[b]{2}{*}{$\begin{array}{l}\text { p Value Before } \\
\text { PS Adjustment } †\end{array}$} & \multicolumn{2}{|c|}{ p Value After PS Adjustment } \\
\hline & & & & $\begin{array}{l}\text { PS as Continuous } \\
\text { Covariate } ₫ \S\end{array}$ & $\begin{array}{c}\text { PS } \\
\text { Stratification§T }\end{array}$ \\
\hline Age (yrs) & & & 0.369 & 0.997 & 0.873 \\
\hline Median [IQR] & 44 [39-49] & 44 [38-49] & & & \\
\hline Mean \pm SD & $44.5 \pm 8.8$ & $43.9 \pm 8.8$ & & & \\
\hline Height (in) & & & 0.622 & 0.998 & 0.946 \\
\hline Median [IQR] & 67 [64-71] & 67 [64-71] & & & \\
\hline Mean \pm SD & $67.7 \pm 4.1$ & $67.5 \pm 4.2$ & & & \\
\hline Weight (lbs) & & & 0.565 & 0.998 & 0.962 \\
\hline Median [IQR] & 180 [154-218] & 181 [155-210] & & & \\
\hline Mean \pm SD & $186.9 \pm 45.0$ & $184.7 \pm 41.5$ & & & \\
\hline NDI score & & & 0.499 & 0.997 & 0.952 \\
\hline Median [IQR] & 54 [44-66] & 58 [44-68] & & & \\
\hline Mean \pm SD & $55.5 \pm 14.7$ & $56.4 \pm 15.9$ & & & \\
\hline SF-36 PCS score & & & 0.775 & 0.999 & 0.898 \\
\hline Median [IQR] & 32.4 [27.4-36.7] & $31.5[27.1-36.6]$ & & & \\
\hline Mean \pm SD & $32.2 \pm 7.4$ & $32.0 \pm 7.5$ & & & \\
\hline SF-36 MCS score & & & 0.078 & 0.993 & 0.924 \\
\hline Median [IQR] & $46.5[34.9-53.6]$ & $42.1[33.1-53.0]$ & & & \\
\hline Mean \pm SD & $44.5 \pm 11.5$ & $42.7 \pm 12.4$ & & & \\
\hline Neck pain score & & & 0.190 & 0.995 & 0.987 \\
\hline Median [IQR] & $70[50-81]$ & $72[56-81]$ & & & \\
\hline Mean \pm SD & $60.7 \pm 20.8$ & $69.3 \pm 21.5$ & & & \\
\hline Arm pain score & & & 0.237 & 0.995 & 0.960 \\
\hline Median [IQR] & 64 [40-80] & 67 [42-83] & & & \\
\hline Mean \pm SD & $59.6 \pm 26.3$ & $62.4 \pm 28.5$ & & & \\
\hline Female & $151(53.9)$ & $143(54.0)$ & 1.000 & 1.000 & 0.881 \\
\hline Race & & & 0.075 & 0.997 & 0.708 \\
\hline Caucasian & $271(96.8)$ & $243(91.7)$ & & & \\
\hline Black & $7(2.5)$ & $13(4.9)$ & & & \\
\hline Asian & $0(0.0)$ & $2(0.8)$ & & & \\
\hline Hispanic & $1(0.4)$ & $6(2.3)$ & & & \\
\hline Other & $1(0.4)$ & $1(0.4)$ & & & \\
\hline Marital status & & & 0.109 & 0.990 & 0.749 \\
\hline Single & 40 (14.3) & 32 (12.1) & & & \\
\hline Married & $189(67.5)$ & $204(77.0)$ & & & \\
\hline Divorced & $42(15.0)$ & $24(9.1)$ & & & \\
\hline Separated & $7(2.5)$ & $3(1.1)$ & & & \\
\hline Widowed & $2(0.7)$ & $2(0.8)$ & & & \\
\hline Education level & & & 0.063 & 0.991 & 0.877 \\
\hline$<$ High school & $15(5.4)$ & $14(5.3)$ & & & \\
\hline High school & 57 (20.5) & 77 (29.2) & & & \\
\hline$>$ High school & $206(74.1)$ & $173(65.5)$ & & & \\
\hline Workers' compensation case & $32(11.4)$ & $35(13.2)$ & 0.616 & 0.998 & 0.864 \\
\hline Unresolved spinal litigation case & $34(12.1)$ & $32(12.1)$ & 1.000 & 1.000 & 0.928 \\
\hline Tobacco used & $74(26.4)$ & $92(34.7)$ & 0.045 & 0.991 & 0.893 \\
\hline Alcohol used & $150(53.6)$ & $141(53.2)$ & 1.000 & 1.000 & 0.900 \\
\hline Working before operation & $188(67.1)$ & $166(62.6)$ & 0.312 & 0.996 & 0.968 \\
\hline Nonnarcotic relaxant medication use & $208(74.3)$ & $187(71.1)$ & 0.462 & 0.997 & 0.836 \\
\hline
\end{tabular}


TABLE 3. Patient demographic and preoperative characteristics (continued)

\begin{tabular}{|c|c|c|c|c|c|}
\hline \multirow[b]{2}{*}{ Variable } & \multirow[b]{2}{*}{$\begin{array}{l}\text { Investigational } \\
\qquad(n=280)^{*}\end{array}$} & \multirow[b]{2}{*}{$\begin{array}{c}\text { Control } \\
(n=265)^{*}\end{array}$} & \multirow[b]{2}{*}{$\begin{array}{l}\text { p Value Before } \\
\text { PS Adjustment } †\end{array}$} & \multicolumn{2}{|c|}{ p Value After PS Adjustment } \\
\hline & & & & $\begin{array}{l}\text { PS as Continuous } \\
\text { Covariate } \mp\end{array}$ & $\begin{array}{c}\text { PS } \\
\text { Stratification§ञ }\end{array}$ \\
\hline Weak narcotic medication use & $133(47.7)$ & $127(48.3)$ & 0.954 & 1.000 & 0.843 \\
\hline Strong narcotic medication use & $62(22.2)$ & $58(22.0)$ & 1.000 & 1.000 & 0.995 \\
\hline Muscle relaxant medication use & $100(35.8)$ & $114(43.2)$ & 0.097 & 0.993 & 0.977 \\
\hline Time to start of symptoms & & & 0.488 & 0.999 & 0.992 \\
\hline$<6$ wks & $22(7.9)$ & $15(5.7)$ & & & \\
\hline 6 wks -6 mos & $85(30.4)$ & $89(33.6)$ & & & \\
\hline$>6 \mathrm{mos}$ & $173(61.8)$ & $161(60.8)$ & & & \\
\hline Normal motor functions & $107(38.2)$ & $158(59.6)$ & $<0.001$ & 0.979 & 0.751 \\
\hline Normal sensory functions & $117(41.8)$ & $135(50.9)$ & 0.040 & 0.991 & 0.890 \\
\hline Normal reflexes & $186(66.4)$ & $162(61.1)$ & 0.231 & 0.995 & 0.888 \\
\hline Normal gait score & $262(93.6)$ & $204(77.0)$ & $<0.001$ & 0.881 & 0.467 \\
\hline Positive foraminal compression test & $120(42.9)$ & $144(54.3)$ & 0.009 & 0.989 & 0.875 \\
\hline Treatment level & & & 0.201 & 0.989 & 0.981 \\
\hline C3-4 & $4(1.4)$ & $10(3.8)$ & & & \\
\hline C4-5 & $21(7.5)$ & $15(5.7)$ & & & \\
\hline C5-6 & $147(52.5)$ & $149(56.2)$ & & & \\
\hline C6-7 & $108(38.6)$ & $91(34.3)$ & & & \\
\hline C6-7 & $108(38.6)$ & $91(34.3)$ & & & \\
\hline
\end{tabular}

PS = propensity score.

* Values are number of patients (\%) unless stated otherwise.

$\dagger$ For continuous variables $p$ values are from ANOVA, and for categorical variables they are from the chi-square test.

$\mp$ For continuous variables $p$ values are from ANCOVA, and for categorical variables they are from logistic regression, both with propensity score as a continuous covariate.

$\S$ For categorical variables with multiple categories, they (except for treatment level) were dichotomized in the logistic regression models for calculating propensity scores in order to increase the model stability and for checking the covariate balance between treatment groups.

If For continuous variables $p$ values are from ANCOVA, and for categorical variables they are from the Cochran-Mantel-Haenszel test.

level that did not remove, modify, or add any components. Examples of reoperations included procedures to remove disc materials and bone fragments, as well as decompression procedures. Secondary surgical interventions occurred in both treatment groups, and results at 24 months are compared in Table 7 . The mean difference in the rate of supplemental fixation procedures between the investigational and the control group was -0.026 (95\% credible interval -0.052 to -0.007$)$. The posterior probability that the investigational group had a lower rate of supplemental fixation procedures was 0.995 , demonstrating statistical superiority over the control group. Excluding external bone growth stimulators from supplemental fixation, rates were similar between the groups. The percentage of patients undergoing secondary surgeries at the adjacent level, cumulatively up to the 24-month follow up, was similar: $2.5 \%$ of investigational and $4.2 \%$ of control patients.
In this study, device- and device/surgical procedure-related AEs were reported in $12.1 \%$ of investigational and $15.5 \%$ of control patients, although the rates were very similar after factoring out the control group-specific nonunion category. The incidence of AEs that were both serious and classified as device- and device/surgical procedure-related events was also similar in the investigational $(5.0 \%)$ and control (4.9\%) groups.

\section{Radiographic Outcomes}

Measurements pertaining to the FSU were made to evaluate maintenance of disc height during the postoperative period. Because of both visualization challenges and the requirement that both 1.5-month and 24-month measurements were needed to achieve FSU success, a success/ failure determination could not be made for approximately $20 \%$ of patients in the investigational group. FSU height

TABLE 4. Comparisons of surgical data

\begin{tabular}{|c|c|c|c|c|c|c|c|}
\hline \multirow[b]{2}{*}{ Parameter } & \multicolumn{2}{|c|}{$\mu_{1}$ (investigational) } & \multicolumn{2}{|c|}{$\mu_{0}$ (control) } & \multicolumn{2}{|c|}{$\mu_{1}-\mu_{0}$} & \multirow{2}{*}{$\begin{array}{l}\text { Probability of } \\
\text { Superiority }\end{array}$} \\
\hline & Mean & $95 \% \mathrm{HPD}$ & Mean & $95 \%$ HPD & Mean & $95 \%$ HPD & \\
\hline Operative time (hrs) & 1.49 & $(1.43,1.56)$ & 1.38 & $(1.31,1.45)$ & 0.11 & $(0.01,0.21)$ & 0.015 \\
\hline Blood loss (ml) & 51 & $(42.2,60.0)$ & 57.1 & $(48.2,66.1)$ & -6.0 & $(-19.3,7.2)$ & 0.817 \\
\hline Hospital stay (days) & 0.98 & $(0.92,1.03)$ & 0.95 & $(0.89,1.01)$ & 0.03 & $(-0.06,0.11)$ & 0.278 \\
\hline
\end{tabular}




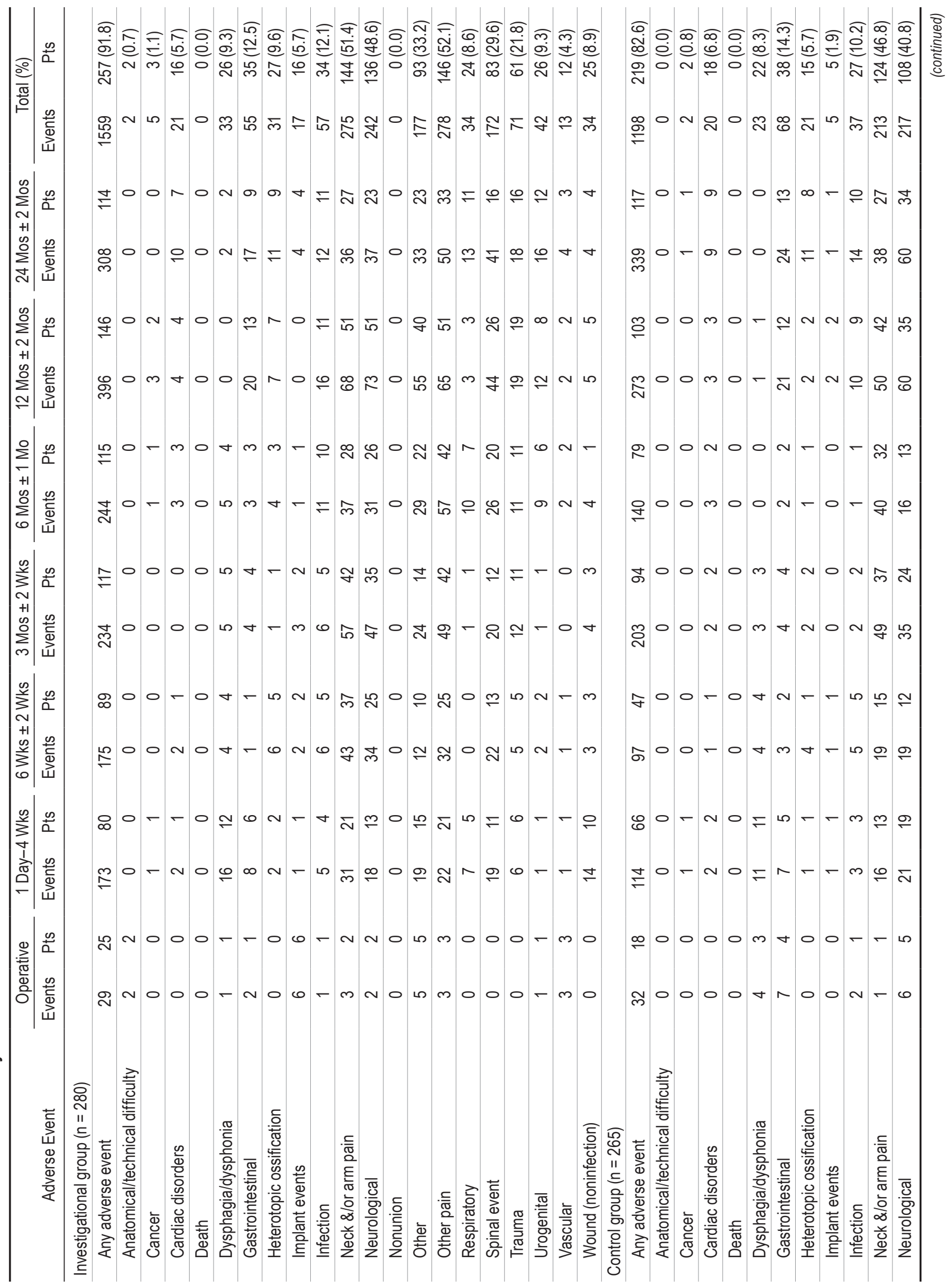




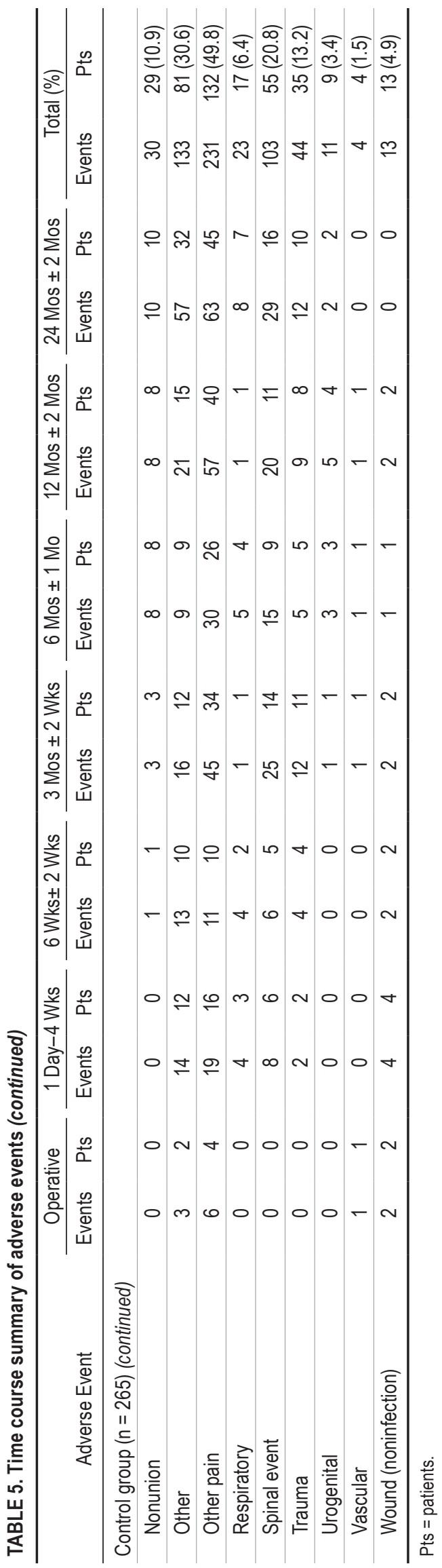

success rates were high for those patients for whom measurements were available, exceeding $90 \%$ for both treatment groups at all 4 postoperative evaluations. Statistical noninferiority was demonstrated with a posterior probability of 0.992 .

Angular motion (Fig. 3) and translational motion at the index level were measured throughout the postoperative course. For the investigational group, mean angular motion was maintained postoperatively at 12 months $\left(7.85^{\circ}\right)$ and 24 months $\left(7.51^{\circ}\right)$, whereas mean translational motion for the postoperative period ranged from $0.90 \mathrm{~mm}$ to 1.03 $\mathrm{mm}$. The independent radiologists at the core laboratory reported bridging bone in $5.95 \%$ of investigational patients.

Motion at levels adjacent to the surgery was also measured at planned postoperative intervals. Preoperatively and at all postoperative measurements, motion was greater in the control group at both the superior and inferior levels. Mean angular motion increased in both the investigational group and the control group at the superior level at 12 months and 24 months, whereas at the inferior level at 24 months, both groups declined compared with the mean motion measured at 12 months (Table 8).

\section{Efficacy End Points}

Compared with preoperative pain and disability assessments, highly significant improvements (all p $<0.001$, paired t-tests) in NDI, SF-36 PCS and MCS, neck pain, and arm pain scores were achieved at 1.5 months and sustained through the patient assessments at 24 months for both the investigational and the control groups. Mean NDI improvements at 12 months and 24 months exceeded 30 points in both treatment groups (Fig. 4).

Success rates, with success generally defined in the protocol as maintenance or improvement compared with preoperative scores, were compared for the secondary end points (except NDI) using Bayesian methods (Table 9). Compared with the control group, the investigational group had a numerically higher rate of NDI success $(\geq$ 15-point improvement), of neurological status success, of arm pain success, and of MCS success. The success rates of FSU height, neck pain, and SF-36 PCS in the investigation group were numerically lower than those in the control group. The posterior probabilities (Fig. 5) that the success rate in the control group was less than $10 \%$ higher than in the investigational group were essentially 1.0 for all outcomes except SF-36 PCS, thus demonstrating statistical noninferiority of the investigational group to the control group for these outcomes. The posterior probabilities that the success rate in the investigational group was higher than control group were 1.000 (approximately), 0.993, and 0.994 for neurological status, SF-36 MCS, and overall success without FSU, respectively. These Bayesian probabilities exceeded the threshold of 0.95 , providing for a conclusion of statistical superiority of the investigational group to the control group.

\section{Treatment Effectiveness and Patient Satisfaction}

Patients were asked to evaluate their overall impression of their treatment effectiveness as a function of pain at each postoperative follow-up interval. The 7 possible 
TABLE 6. Comparisons of adverse events at 24 months*

\begin{tabular}{|c|c|c|c|c|c|c|c|}
\hline \multirow[b]{2}{*}{ Adverse Event } & \multicolumn{2}{|c|}{$p_{1}$ (investigational) } & \multicolumn{2}{|c|}{$\mathrm{p}_{0}$ (control) } & \multicolumn{2}{|r|}{$p_{1}-p_{0}$} & \multirow{2}{*}{$\begin{array}{r}\text { Probability o } \\
\text { Superiority }\end{array}$} \\
\hline & Mean & $95 \%$ HPD & Mean & $95 \%$ HPD & Mean & $95 \%$ HPD & \\
\hline Anatomical/technical difficulty & 0.005 & $(0.000,0.017)$ & 0.000 & $(0.000,0.000)$ & 0.005 & $(0.000,0.017)$ & 0.000 \\
\hline Cancer & 0.011 & $(0.002,0.026)$ & 0.006 & $(0.001,0.019)$ & 0.004 & $(-0.012,0.022)$ & 0.270 \\
\hline Cardiac disorders & 0.054 & $(0.030,0.085)$ & 0.070 & $(0.041,0.105)$ & -0.016 & $(-0.061,0.027)$ & 0.771 \\
\hline Dysphagia/dysphonia & 0.092 & $(0.060,0.130)$ & 0.082 & $(0.051,0.120)$ & 0.010 & $(-0.042,0.061)$ & 0.341 \\
\hline Gastrointestinal & 0.129 & $(0.091,0.172)$ & 0.137 & $(0.096,0.183)$ & -0.008 & $(-0.069,0.054)$ & 0.593 \\
\hline Heterotopic ossification & 0.102 & $(0.068,0.142)$ & 0.050 & $(0.027,0.080)$ & 0.052 & $(0.005,0.100)$ & 0.014 \\
\hline Implant events & 0.057 & $(0.032,0.089)$ & 0.018 & $(0.006,0.038)$ & 0.039 & $(0.006,0.075)$ & 0.011 \\
\hline Infection & 0.119 & $(0.083,0.162)$ & 0.102 & $(0.068,0.143)$ & 0.017 & $(-0.039,0.075)$ & 0.278 \\
\hline Neck \&/or arm pain & 0.520 & $(0.457,0.580)$ & 0.463 & $(0.401,0.527)$ & 0.057 & $(-0.034,0.148)$ & 0.112 \\
\hline Neurological & 0.495 & $(0.433,0.556)$ & 0.398 & $(0.336,0.460)$ & 0.097 & $(0.007,0.190)$ & 0.018 \\
\hline Nonunion & 0.000 & $(0.000,0.000)$ & 0.114 & $(0.076,0.159)$ & -0.114 & $(-0.159,-0.076)$ & $\sim 1.000$ \\
\hline Other & 0.337 & $(0.280,0.396)$ & 0.301 & $(0.245,0.360)$ & 0.036 & $(-0.050,0.120)$ & 0.201 \\
\hline Other pain & 0.513 & $(0.451,0.573)$ & 0.507 & $(0.443,0.570)$ & 0.006 & $(-0.087,0.096)$ & 0.451 \\
\hline Respiratory & 0.083 & $(0.053,0.121)$ & 0.065 & $(0.038,0.099)$ & 0.019 & $(-0.029,0.067)$ & 0.215 \\
\hline Spinal event & 0.314 & $(0.258,0.372)$ & 0.189 & $(0.142,0.241)$ & 0.125 & $(0.045,0.203)$ & 0.001 \\
\hline Trauma & 0.212 & $(0.163,0.264)$ & 0.135 & $(0.095,0.181)$ & 0.077 & $(0.007,0.147)$ & 0.016 \\
\hline Urogenital & 0.087 & $(0.055,0.127)$ & 0.035 & $(0.016,0.062)$ & 0.052 & $(0.010,0.098)$ & 0.010 \\
\hline Vascular & 0.046 & $(0.024,0.075)$ & 0.012 & $(0.003,0.027)$ & 0.034 & $(0.008,0.066)$ & 0.006 \\
\hline Wound (noninfection) & 0.096 & $(0.062,0.135)$ & 0.042 & $(0.021,0.071)$ & 0.053 & $(0.008,0.100)$ & 0.010 \\
\hline Any adverse event & 0.922 & $(0.887,0.951)$ & 0.820 & $(0.769,0.867)$ & 0.102 & $(0.041,0.165)$ & 0.001 \\
\hline
\end{tabular}

* Compared with the control group, the investigational group had a significantly lower rate of nonunion adverse events, but the rates of anatomical difficulty, heterotopic ossification, implant events, neurological adverse event, spinal event, trauma, urogenital adverse event, vascular adverse event, and wound were greater in the investigational group than in the control group.

responses ranged from "completely recovered" to "vastly worsened." At 12 months and 24 months following surgery, $86.1 \%$ and $86.6 \%$, respectively, of the investigational patients indicated that they had either "completely recovered" or were "much improved." In the control group, the rates were $74.9 \%$ and $80.8 \%$, respectively.

At the same intervals, patients were asked to respond to 3 statements pertaining to their satisfaction with their treatment (Table 10). Patient responses at 12 months and 24 months after surgery indicated high satisfaction in both treatment groups, with rates of "definitely true" or "mostly true" responses ranging from $82.2 \%$ to $90.7 \%$.

\section{Overall Success}

A patient was determined to be an overall success only if all 5 variables in the FDA-defined measure were successfully achieved: NDI success; neurological success; disc height (FSU height) success; no serious AE classified as implant or implant/surgical procedure associated; and no secondary surgical procedure classified as a "failure." The rate of overall success in the investigational group exceeded the rate in the control group without FSU height success by 0.111 (95\% credible interval 0.026-0.196), and with FSU 0.031 (95\% credible interval -0.07 to 0.135$)$, respectively (Table 9). The posterior probability that the overall success

TABLE 7. Comparisons of secondary surgical events at 24 months*

\begin{tabular}{|c|c|c|c|c|c|c|c|c|c|}
\hline \multirow[b]{2}{*}{ Surgical Event } & \multicolumn{3}{|c|}{$p_{1}$ (investigational) } & \multicolumn{3}{|c|}{$\mathrm{p}_{0}$ (control) } & \multicolumn{2}{|r|}{$p_{1}-p_{0}$} & \multirow{2}{*}{$\begin{array}{l}\text { Probability of } \\
\text { Superiority }\end{array}$} \\
\hline & No. of Pts & Mean & 95\% HPD & No. of Pts & Mean & 95\% HPD & Mean & $95 \%$ HPD & \\
\hline Revisions & 1 & 0.004 & $(0.000,0.013)$ & 5 & 0.016 & $(0.004,0.037)$ & -0.013 & $(-0.034,0.003)$ & 0.950 \\
\hline Removals & 10 & 0.037 & $(0.018,0.063)$ & 11 & 0.038 & $(0.018,0.066)$ & -0.001 & $(-0.036,0.033)$ & 0.525 \\
\hline $\begin{array}{l}\text { Supplemental } \\
\text { fixation }\end{array}$ & 2 & 0.005 & $(0.001,0.015)$ & 8 & 0.031 & $(0.014,0.057)$ & -0.026 & $(-0.052,-0.007)$ & 0.995 \\
\hline Reoperations & 3 & 0.011 & $(0.002,0.026)$ & 2 & 0.006 & $(0.001,0.019)$ & 0.004 & $(-0.011,0.021)$ & 0.266 \\
\hline Others & 62 & 0.219 & $(0.170,0.272)$ & 50 & 0.190 & $(0.144,0.240)$ & 0.030 & $(-0.043,0.103)$ & 0.211 \\
\hline
\end{tabular}

* The mean difference in the rate of supplemental fixation procedures between the investigational group and the control group was -0.026 ( $95 \%$ credible interval was -0.052 to -0.007$)$. The posterior probability that the investigational group had a lower rate of supplemental fixation procedures was 0.995 , demonstrating a statistical superiority of the investigational group over the control group. 

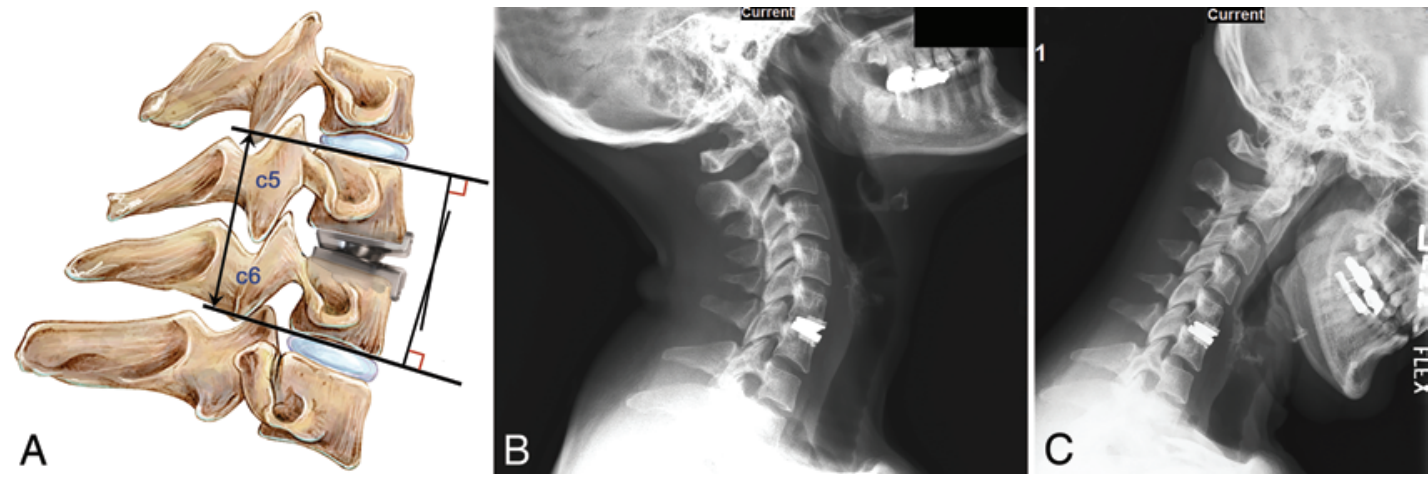

FIG. 3. Segmental motion was measured using the Cobb method (A) on lateral dynamic flexion (B) and extension (C) radiographs. Radiographic success required angular motion at the level of surgery to be $>4^{\circ}$ but $<20^{\circ}$ at each postoperative interval. Copyright Matthew F. Gornet. Published with permission.

rate (without FSU) in the investigational group was higher than the control group was 0.994 , indicating a statistically significant superiority. Sensitivity analyses using the per protocol data set or the per protocol in-window data set produced similar results (data not shown).

\section{Return to Work}

Patient work status was recorded preoperatively and at each follow-up visit. Prior to surgery, $67.1 \%$ of investigational and $62.6 \%$ of control patients were reported to be working. At the 24-month follow-up, the percentage of patients working was similar in the investigational $(73.4 \%)$ and control (75.9\%) groups. However, a Kaplan-Meier time-to-event analysis demonstrated that PRESTIGE LP patients returned to work a median 20 days sooner than ACDF patients, and in the Cox regression analysis, the adjusted hazard ratio was $1.28(95 \%$ CI $1.04-1.59, \mathrm{p}=0.02)$ in favor of investigational patients.

\section{Discussion}

Cervical disc arthroplasty was developed with the goal of safely providing patients with comparable pain and disability improvement to ACDF while maintaining physiological global cervical motion and thereby potentially avoiding many of the reported complications of cervical arthrodesis for single-level disease. In this study, as with the other FDA-approved cervical disc prostheses, PRESTIGE LP was found to provide as good or better pain and disability outcomes compared with ACDF 24 months after surgery. The investigational devices were likewise found to be as safe as the control treatments, based on AEs, second surgeries, and neurological status. Patient satisfaction was high for both treatment groups in each study. The cumulative Level 1 evidence from thousands of patients in these very large clinical trials provides compelling support for surgical treatment of this cervical DDD patient population using either ACDF or CDA.

Using a historical cohort in this device study is admittedly subordinate in preference to a randomized trial. Nevertheless, the statistical analysis plan, as part of the entire protocol, was extensively reviewed with and approved by the FDA. Bayesian propensity score techniques (logistic regression model) used by the original designers of the

TABLE 8. Postoperative mean angular motion at adjacent levels

\begin{tabular}{|c|c|c|c|c|c|c|}
\hline \multirow[b]{2}{*}{ Time Point } & \multicolumn{3}{|c|}{ Investigational $(n=280)$} & \multicolumn{3}{|c|}{ Control $(n=265)$} \\
\hline & No. of Pts & Mean \pm SD & $p$ Value & No. of Pts & Mean \pm SD & $\mathrm{p}$ Value \\
\hline \multicolumn{7}{|l|}{6 wks } \\
\hline Change in angulation at the segment above $\left(^{\circ}\right)$ & 266 & $-0.77 \pm 3.61$ & $<0.001$ & 187 & $-1.13 \pm 4.39$ & $<0.001$ \\
\hline Change in angulation at the segment below $\left(^{\circ}\right)$ & 172 & $-0.25 \pm 3.17$ & 0.298 & 86 & $0.70 \pm 3.67$ & 0.081 \\
\hline \multicolumn{7}{|l|}{$3 \mathrm{mos}$} \\
\hline Change in angulation at the segment above $\left({ }^{\circ}\right)$ & 264 & $0.32 \pm 3.85$ & 0.175 & 194 & $0.06 \pm 4.27$ & 0.841 \\
\hline Change in angulation at the segment below $\left(^{\circ}\right)$ & 174 & $0.29 \pm 3.48$ & 0.266 & 91 & $1.21 \pm 3.71$ & 0.002 \\
\hline \multicolumn{7}{|l|}{$6 \mathrm{mos}$} \\
\hline Change in angulation at the segment above $\left(^{\circ}\right)$ & 263 & $0.82 \pm 3.84$ & $<0.001$ & 198 & $0.53 \pm 4.26$ & 0.084 \\
\hline Change in angulation at the segment below $\left(^{\circ}\right)$ & 166 & $0.65 \pm 3.69$ & 0.025 & 94 & $0.99 \pm 3.93$ & 0.017 \\
\hline \multicolumn{7}{|l|}{12 mos } \\
\hline Change in angulation at the segment above $\left(^{\circ}\right)$ & 267 & $1.27 \pm 3.75$ & $<0.001$ & 188 & $1.32 \pm 4.41$ & $<0.001$ \\
\hline Change in angulation at the segment below $\left(^{\circ}\right)$ & 166 & $1.11 \pm 3.47$ & $<0.001$ & 95 & $1.89 \pm 4.50$ & $<0.001$ \\
\hline \multicolumn{7}{|l|}{24 mos } \\
\hline Change in angulation at the segment above $\left({ }^{\circ}\right)$ & 262 & $1.88 \pm 3.84$ & $<0.001$ & 187 & $1.04 \pm 4.60$ & 0.002 \\
\hline Change in angulation at the segment below $\left(^{\circ}\right)$ & 161 & $1.13 \pm 3.75$ & $<0.001$ & 94 & $1.28 \pm 4.28$ & 0.005 \\
\hline
\end{tabular}




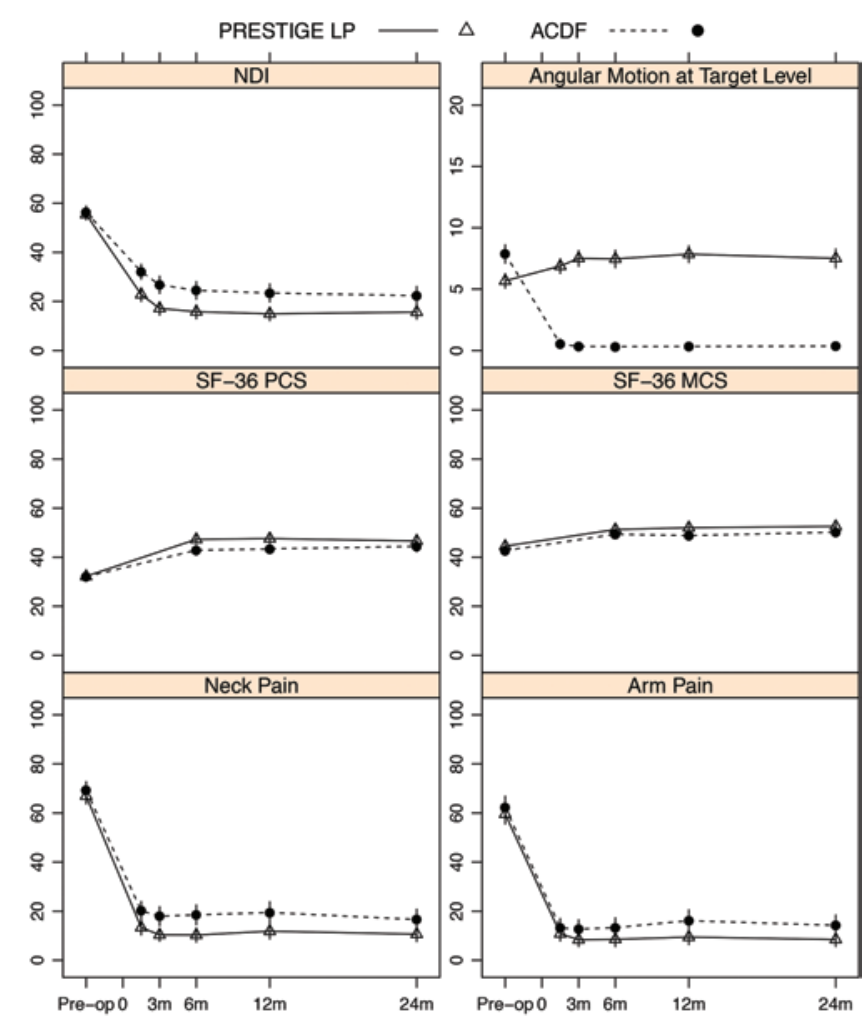

FIG. 4. Mean NDI score, angular motion at target level, PCS, MCS, neck pain score, and arm pain score of the treatment groups at different time points. Vertical bars indicate $99 \%$ Cls of the means.

study - and again by the independent statisticians-balanced all covariates, removed the opportunity for variation caused by cofounders, and validated the statistical comparability of the 2 study groups.

Although the surgical approach is essentially the same for cervical arthroplasty or ACDF, there are subtle differences in the procedures that could lead to statistical differences in postoperative neurological test results. No statistical difference was reported at 24 months in at least 1 study, although most of the cervical arthroplasty IDE studies did report a difference at 24 months. The onset of adjacent-level changes in the fusion group may also have contributed to a decline in neurological outcome over time.

Safety assessments are a critical component of the FDA approval process for investigational devices. In this study, overall AE rates were higher in the investigational group than in the historical control group; this may be attributable in part to the high follow-up rates in the investigational group.

One of the $8 \mathrm{AE}$ categories in which the control group had statistically lower rates than the investigational group was heterotopic ossification, a finding reported by the investigator surgeons without third party review and without reference to grading or severity. A total of 31 heterotopic ossification AEs were reported in 27 investigational patients (9.6\%) compared with 21 events in 15 patients (5.7\%) in the control group. Despite the lack of formal grading, this compares favorably with risks of heterotopic ossification up to 24 months after CDA that were reported in other FDA studies of single-level CDA. ${ }^{23,29}$ The independent radiologist findings in this study, while not evaluating heterotopic ossification per se, did report on the incidence of bridging bone (5.95\%) in investigational patients at 24 months, defined as evidence of a continuous connection of trabecular bone between vertebral bodies.

There was 1 revision procedure in the investigational group. After the device was reported to have migrated at approximately 2 months after the index surgery, the artificial disc device was removed and replaced with the same device in a different size. Thaler et al. reported high rates of undersizing of the most commonly used cervical disc implants, including the PRESTIGE LP, and warned of potential consequences, including subsidence, migration, heterotopic ossification, and biomechanical failure caused by incorrect center of rotation and load distribution. ${ }^{28}$

As a general rule, patients tend to return to work when their pain has improved to the point that they are able to work. The patient in this study is asked at each followup after surgery if he/she is employed. If not, the patient is asked if this is because of neck pain. Following surgery, CDA patients report NDI improvement much more quickly than ACDF patients, particularly at 6 weeks and 3 months postoperatively. Although it is possible for surgeon preference to be a factor, pain and disability improvements track closely with return to work after surgery.

Adoption and utilization rates for CDA continued to lag behind ACDF following FDA approval in 2007 of the initial devices available in the US: PRESTIGE, BRYAN Cervical Disc, and ProDisc-C. ${ }^{17}$ Four- to 5-year data are now

TABLE 9. Comparisons of efficacy and neurological variables at 24 months

\begin{tabular}{|c|c|c|c|c|c|c|c|c|}
\hline \multirow[b]{2}{*}{ Variable } & \multicolumn{2}{|c|}{$p_{1}$ (investigational) } & \multicolumn{2}{|c|}{$\mathrm{p}_{0}$ (control) } & \multicolumn{2}{|r|}{$\overline{p_{0}-p_{1}}$} & \multicolumn{2}{|c|}{ Probability of } \\
\hline & Mean & $95 \% \mathrm{HPD}$ & Mean & $95 \% \mathrm{HPD}$ & Mean & $95 \% \mathrm{HPD}$ & Noninferiority & Superiority \\
\hline NDI & 0.872 & $(0.828,0.911)$ & 0.824 & $(0.768,0.873)$ & -0.048 & $(-0.118,0.019)$ & $\sim 1.000$ & 0.916 \\
\hline Neurological status & 0.935 & $(0.901,0.961)$ & 0.835 & $(0.780,0.884)$ & -0.100 & $(-0.162,-0.039)$ & $\sim 1.000$ & $\sim 1.000$ \\
\hline FSU & 0.917 & $(0.876,0.951)$ & 0.951 & $(0.911,0.979)$ & 0.034 & $(-0.022,0.086)$ & 0.992 & 0.104 \\
\hline Neck pain & 0.964 & $(0.937,0.983)$ & 0.974 & $(0.947,0.991)$ & 0.010 & $(-0.024,0.043)$ & $\sim 1.000$ & 0.269 \\
\hline Arm pain & 0.967 & $(0.942,0.985)$ & 0.947 & $(0.912,0.974)$ & -0.019 & $(-0.059,0.018)$ & $\sim 1.000$ & 0.843 \\
\hline SF-36 PCS & 0.828 & $(0.778,0.873)$ & 0.875 & $(0.827,0.917)$ & 0.047 & $(-0.022,0.115)$ & 0.938 & 0.09 \\
\hline SF-36 MCS & 0.786 & $(0.734,0.834)$ & 0.682 & $(0.614,0.744)$ & -0.105 & $(-0.190,-0.020)$ & $\sim 1.000$ & 0.993 \\
\hline Overall success (w/o FSU) & 0.789 & $(0.736,0.838)$ & 0.678 & $(0.613,0.741)$ & -0.111 & $(-0.196,-0.026)$ & $\sim 1.000$ & 0.994 \\
\hline Overall success (w/ FSU) & 0.688 & $(0.623,0.749)$ & 0.657 & $(0.579,0.731)$ & -0.031 & $(-0.135,0.070)$ & 0.995 & 0.722 \\
\hline
\end{tabular}




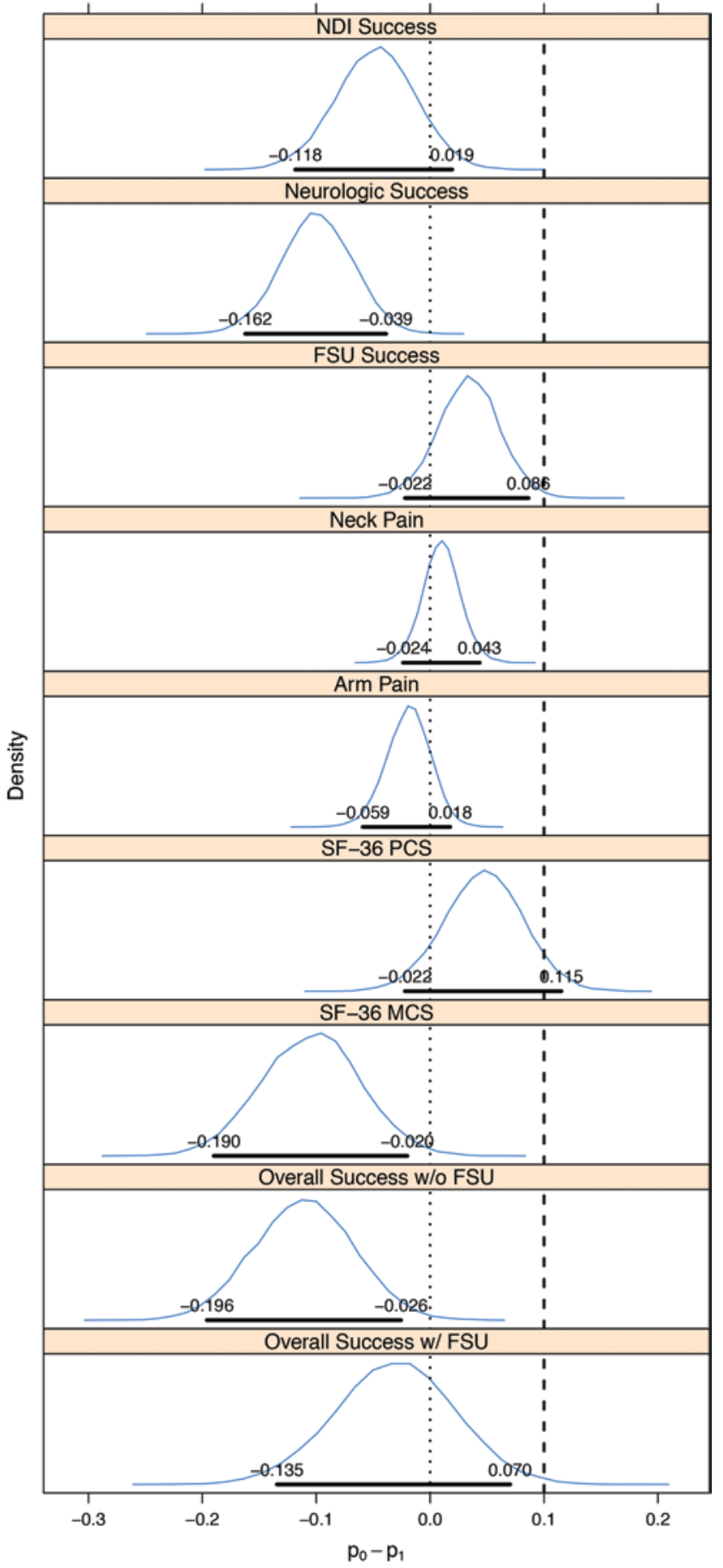

FIG. 5. Posterior distributions of differences in success rates of efficacy and neurological variables between the 2 treatment groups. Horizontal bold lines indicate $95 \%$ HPD, upper and lower limits of which are also labeled. The dashed vertical line is the upper limit of noninferiority, and the dotted vertical line is the upper limit of superiority.

published in the peer-reviewed literature for these devices, providing the first confirmatory Level 1 evidence that disc arthroplasty patients do at least as well as or better than ACDF control patients not just after 24 months, but also on a longer-term basis. ${ }^{5,25,34}$ For PRESTIGE LP and other more recently developed prostheses, if long-term results
TABLE 10. Patient satisfaction at 24 months

\begin{tabular}{|c|c|c|}
\hline \multirow[b]{2}{*}{ Level of Satisfaction } & \multicolumn{2}{|c|}{ No. of Pts (\%) } \\
\hline & $\begin{array}{l}\text { Investigational } \\
\quad(n=270)\end{array}$ & $\begin{array}{l}\text { Control } \\
(\mathrm{n}=219)\end{array}$ \\
\hline \multicolumn{3}{|c|}{$\begin{array}{l}\text { I am satisfied w/ the results of my } \\
\text { surgery }\end{array}$} \\
\hline Definitely true & $198(73.3)$ & $130(59.4)$ \\
\hline Mostly true & $45(16.7)$ & $62(28.3)$ \\
\hline Do not know & $18(6.7)$ & $11(5.0)$ \\
\hline Mostly false & $5(1.9)$ & $5(2.3)$ \\
\hline Definitely false & $4(1.5)$ & $11(5.0)$ \\
\hline \multicolumn{3}{|l|}{$\begin{array}{l}\text { I was helped as much as I } \\
\text { thought I would be }\end{array}$} \\
\hline Definitely true & $186(68.9)$ & $133(60.7)$ \\
\hline Mostly true & $50(18.5)$ & $47(21.5)$ \\
\hline Do not know & $21(7.8)$ & $11(5.0)$ \\
\hline Mostly false & $10(3.7)$ & $14(6.4)$ \\
\hline Definitely false & $3(1.1)$ & $14(6.4)$ \\
\hline \multicolumn{3}{|l|}{$\begin{array}{l}\text { All things considered I would } \\
\text { have the surgery again }\end{array}$} \\
\hline Definitely true & $216(80.0)$ & $154(70.3)$ \\
\hline Mostly true & $29(10.7)$ & $29(13.2)$ \\
\hline Do not know & $17(6.3)$ & $24(11.0)$ \\
\hline Mostly false & $3(1.1)$ & $5(2.3)$ \\
\hline Definitely false & $5(1.9)$ & $7(3.2)$ \\
\hline
\end{tabular}

also confirm initial outcomes trends, this will offer the potential for additional support of CDA as a substitute for ACDF in appropriately selected patients with single-level degenerative disc disease. Meanwhile, debate continues regarding the benefits of $\mathrm{CDA}$ over $\mathrm{ACDF}$, in particular the prospect of reduced adjacent segment degeneration and reoperation rates, $, 12,20,24,35$ as additional long-term evidence continues to be published.

\section{Conclusions}

The PRESTIGE LP Cervical Disc maintains mean postoperative segmental motion while providing the potential for biomechanical stability. Investigational patients reported significantly improved pain and disability outcomes, as good or better compared with ACDF, up to 24 months after surgery.

\section{Acknowledgments}

We thank the other participating investigators and their clinical staff for their participation and contribution to the trial: Chad D. Abernathey, MD; Vincent Arlet, MD; Todd Bonvallet, MD; Thomas Briggs, MD; Paul A. Broadstone, MD; William Bronson, MD; Andrew Casden, MD; Jeffrey F. Cattorini, MD; Wade M. Ceola, MD; Mark Crabtree, MD; Brian Cuddy, MD; Edwin J. Cunningham, MD; John Demakas, MD; John Dorchak, MD; Eric Elowitz, MD; David Gruber, MD; Robert J. Hacker, MD; Regis W. Haid Jr., MD; Jeffrey Hirschauer, MD; Theodore Jacobs, MD; Ross Jenkins, MD; Keith A. Kattner, DO; George H. Khoury, MD; P. Jeffrey Lewis, MD; Charles Mace, MD; R. Dean Martz, MD; Jean Pierre Mobasser, MD; Brent C. Morgan, MD; Loren Mouw, MD; Emilio Nardone, MD; Michael G. Neuwirth, MD; Arthur Pacult, MD; 
Richard Pearce, MD; John Pollina, MD; Eric Potts, MD; Salim Rahman, MD; Stephen Rawe, MD, PhD; Joseph Riina, MD; James Robinson, MD; Patrick Ryan, MD; Rick C. Sasso, MD; Paul Sawin, MD; David D. Schwartz, MD; Chris I. Shaffrey, MD; Rebecca E. Stachniak, MD; Robert Strang, MD; Brian R. Subach, MD; John R. Tompkins, MD; and Curtis Worthington, MD.

\section{References}

1. Beutler WJ, Sweeney CA, Connolly PJ: Recurrent laryngeal nerve injury with anterior cervical spine surgery risk with laterality of surgical approach. Spine (Phila Pa 1976) 26:1337-1342, 2001

2. Bohlman HH, Emery SE, Goodfellow DB, Jones PK: Robinson anterior cervical discectomy and arthrodesis for cervical radiculopathy. Long-term follow-up of one hundred and twenty-two patients. J Bone Joint Surg Am 75:1298-1307, 1993

3. Boselie TFM, Willems PC, van Mameren H, de Bie RA, Benzel EC, van Santbrink H: Arthroplasty versus fusion in single-level cervical degenerative disc disease: a Cochrane review. Spine (Phila Pa 1976) 38:E1096-E1107, 2013

4. Brown JA, Havel P, Ebraheim N, Greenblatt SH, Jackson WT: Cervical stabilization by plate and bone fusion. Spine (Phila Pa 1976) 13:236-240, 1988

5. Burkus JK, Haid RW, Traynelis VC, Mummaneni PV: Longterm clinical and radiographic outcomes of cervical disc replacement with the Prestige disc: results from a prospective randomized controlled clinical trial. J Neurosurg Spine 13:308-318, 2010

6. Connolly PJ, Esses SI, Kostuik JP: Anterior cervical fusion: outcome analysis of patients fused with and without anterior cervical plates. J Spinal Disord 9:202-206, 1996

7. Cummins BH, Robertson JT, Gill SS: Surgical experience with an implanted artificial cervical joint. J Neurosurg 88:943-948, 1998

8. Davis RJ, Kim KD, Hisey MS, Hoffman GA, Bae HW, Gaede SE, et al: Cervical total disc replacement with the Mobi-C cervical artificial disc compared with anterior discectomy and fusion for treatment of 2-level symptomatic degenerative disc disease: a prospective, randomized, controlled multicenter clinical trial: clinical article. J Neurosurg Spine 19:532-545, 2013

9. DeAngelis CD, Fontanarosa PB: The importance of independent academic statistical analysis. Biostatistics 11:383-384, 2010

10. Fraser JF, Härtl R: Anterior approaches to fusion of the cervical spine: a metaanalysis of fusion rates. J Neurosurg Spine 6:298-303, 2007

11. Griffith SL, Shelokov AP, Büttner-Janz K, LeMaire JP, Zeegers WS: A multicenter retrospective study of the clinical results of the LINK SB Charité intervertebral prosthesis. The initial European experience. Spine (Phila Pa 1976) 19:18421849,1994

12. Harrod CC, Hilibrand AS, Fischer DJ, Skelly AC: Adjacent segment pathology following cervical motion-sparing procedures or devices compared with fusion surgery: a systematic review. Spine (Phila Pa 1976) 37 (22 Suppl):S96-S112, 2012

13. Hilibrand AS, Carlson GD, Palumbo MA, Jones PK, Bohlman HH: Radiculopathy and myelopathy at segments adjacent to the site of a previous anterior cervical arthrodesis. J Bone Joint Surg Am 81:519-528, 1999

14. Kaiser MG, Haid RW Jr, Subach BR, Barnes B, Rodts GE Jr: Anterior cervical plating enhances arthrodesis after discectomy and fusion with cortical allograft. Neurosurgery 50:229-238, 2002

15. Kim HJ, Kelly MP, Ely CG, Dettori JR, Riew KD: The risk of adjacent-level ossification development after surgery in the cervical spine: are there factors that affect the risk? A systematic review. Spine (Phila Pa 1976) 37 (22 Suppl):S65S74, 2012

16. Krumholz HM, Ross JS: A model for dissemination and independent analysis of industry data. JAMA 306:1593-1594, 2011

17. Lu Y, McAnany SJ, Hecht AC, Cho SK, Qureshi SA: Utilization trends of cervical artificial disc replacement after FDA approval compared with anterior cervical fusion: adoption of new technology. Spine (Phila Pa 1976) 39:249-255, 2014

18. McDowell I, Newell C: Measuring Health: A Guide to Rating Scales and Questionnaires, ed 2. New York: Oxford University Press, 1996

19. McHorney CA, Ware JE Jr, Lu JF, Sherbourne CD: The MOS 36-item Short-Form Health Survey (SF-36): III. Tests of data quality, scaling assumptions, and reliability across diverse patient groups. Med Care 32:40-66, 1994

20. Moatz B, Tortolani PJ: Cervical disc arthroplasty: Pros and cons. Surg Neurol Int 3 (Suppl 3):S216-S224, 2012

21. Mummaneni PV, Burkus JK, Haid RW, Traynelis VC, Zdeblick TA: Clinical and radiographic analysis of cervical disc arthroplasty compared with allograft fusion: a randomized controlled clinical trial. J Neurosurg Spine (Phila Pa 1976) 6:198-209, 2007

22. Murrey D, Janssen M, Delamarter R, Goldstein J, Zigler J, Tay B, et al: Results of the prospective, randomized, controlled multicenter Food and Drug Administration investigational device exemption study of the ProDisc-C total disc replacement versus anterior discectomy and fusion for the treatment of 1-level symptomatic cervical disc disease. Spine J 9:275-286, 2009

23. Phillips FM, Lee JYB, Geisler FH, Cappuccino A, Chaput $\mathrm{CD}, \mathrm{DeV}$ ine JG, et al: A prospective, randomized, controlled clinical investigation comparing PCM cervical disc arthroplasty with anterior cervical discectomy and fusion. 2-year results from the US FDA IDE clinical trial. Spine (Phila Pa 1976) 38:E907-E918, 2013

24. Riew KD, Schenk-Kisser JM, Skelly AC: Adjacent segment disease and C-ADR: promises fulfilled? Evid Based Spine Care J 3 (S1):39-46, 2012

25. Sasso RC, Anderson PA, Riew KD, Heller JG: Results of cervical arthroplasty compared with anterior discectomy and fusion: four-year clinical outcomes in a prospective, randomized controlled trial. J Bone Joint Surg Am 93:1684-1692, 2011

26. Sasso RC, Smucker JD, Hacker RJ, Heller JG: Clinical outcomes of BRYAN cervical disc arthroplasty: a prospective, randomized, controlled, multicenter trial with 24-month follow-up. J Spinal Disord Tech 20:481-491, 2007

27. Smith GW, Robinson RA: The treatment of certain cervicalspine disorders by anterior removal of the intervertebral disc and interbody fusion. J Bone Joint Surg Am 40-A:607-624, 1958

28. Thaler M, Hartmann S, Gstöttner M, Lechner R, Gabl M, Bach C: Footprint mismatch in total cervical disc arthroplasty. Eur Spine J 22:759-765, 2013

29. Upadhyaya CD, Wu JC, Trost G, Haid RW, Traynelis VC, Tay B, et al: Analysis of the three United States Food and Drug Administration investigational device exemption cervical arthroplasty trials. J Neurosurg Spine 16:216-228, 2012

30. Vaccaro A, Beutler W, Peppelman W, Marzluff JM, Highsmith J, Mugglin A, et al: Clinical outcomes with selectively constrained SECURE-C cervical disc arthroplasty: two-year results from a prospective, randomized, controlled, multicenter investigational device exemption study. Spine (Phila Pa 1976) 38:2227-2239, 2013

31. World Health Organization: Toxic effects, in WHO Handbook for Reporting Results of Cancer Treatment. Geneva: World Health Organization, 1979, pp 14-22 
32. Yue WM, Brodner W, Highland TR: Long-term results after anterior cervical discectomy and fusion with allograft and plating: a 5- to 11-year radiologic and clinical follow-up study. Spine (Phila Pa 1976) 30:2138-2144, 2005

33. Zigler JE: Clinical results with ProDisc: European experience and U.S. investigation device exemption study. Spine (Phila Pa 1976) 28:S163-S166, 2003

34. Zigler JE, Delamarter R, Murrey D, Spivak J, Janssen M: ProDisc-C and anterior cervical discectomy and fusion as surgical treatment for single-level cervical symptomatic degenerative disc disease: five-year results of a Food and Drug Administration study. Spine (Phila Pa 1976) 38:203-209, 2013

35. Zigler JE, Glenn J, Delamarter RB: Five-year adjacent-level degenerative changes in patients with single-level disease treated using lumbar total disc replacement with ProDisc-L versus circumferential fusion. J Neurosurg Spine 17:504511,2012

\section{Author Contributions}

Conception and design: Gornet, Burkus, Shaffrey. Acquisition of data: Gornet, Burkus, Shaffrey. Analysis and interpretation of data: Gornet, Burkus, Shaffrey, Nian, Harrell. Drafting the article: Gornet, Burkus, Argires, Nian, Harrell. Critically revising the article: Gornet, Shaffrey, Nian, Harrell. Reviewed submitted version of manuscript: Burkus, Shaffrey, Argires, Nian, Harrell. Approved the final version of the manuscript on behalf of all authors: Gornet. Statistical analysis: Nian, Harrell. Administrative/technical/material support: Gornet. Study supervision: Burkus.

\section{Correspondence}

Matthew F. Gornet, c/o Spine Research Center, 14825 N. Outer Forty Rd., Ste.320, St. Louis, MO 63017.email: mfgspine@ gmail.com. 